\title{
Makna Lirik Nyanyian Andung Dalam Upacara Kematian Sarimatua Pada Masyarakat Batak Toba di Samosir
}

\author{
Daniel Yosmar Heyman Manalu ${ }^{1}$
}

\begin{abstract}
This study discusses the function and meaning of lyric singing in the ceremony of sarimatua death in Batak Toba society in Samosir. In general, there are problems identified in this study. The main problem is hata andung is rarely used by the Toba Batak community. Batak Toba community more often use the Batak Toba language because not many people Toba Batak who understand about the meaning of andung the truth. For that language andung should be used with hata andung no longer used, so it does not have the value of the tradition attached to the Batak Toba community in Samosir. study conducted during the period of four months, from the beginning of February 2017 to May 2017.

To discuss the problem then used the theory of Abdul Chaer in assessing the function and meaning, cultural values contained in andung sarimatua Ompu Juan Boru. The results of this study resulted in some conclusions such as singing andung lacks existence in the Batak community because, the speakers at the ceremony andung Toba batak community dead at the present time is very difficult to find. This andung tradition is considered no longer suitable for today. Some of the factors that result in shifts and changes in the current andung sarimatua traditions are religion, language, and the use of musical instruments.

The function of the andung tradition at present in the Toba Batak community death ceremony include: the function of expression of sadness and the closeness of relationships and respect for the deceased family. The meaning contained in andung sarimatua reveals all the feelings and tells the contents of his heart to his deceased mother, tells many things, the longing of sipangandung to uncle and grandfather who have long died also participated expressed and send greetings to them, and expect her mother still can protect his descendants. Cultural values contained in the tradition andung in the ceremony of death sarimatua Batak Toba community today is the value of hasangapon, hagabeon, and hamoraon.
\end{abstract}

Keywords: Sarimatua, Batak Toba, Lammentation.

\begin{abstract}
Abstrak
Penelitian ini membahas fungsi dan makna lirik nyanyian andung dalam upacara kematian sarimatua pada masyarakat Batak Toba di Samosir. Secara umum, terdapat persoalan yang diidentifikasi dalam penelitian ini. Masalah utamanya adalah hata andung sudah jarang digunakan masyarakat Batak Toba. Masyarakat Batak Toba lebih sering menggunakan Bahasa Batak Toba karena tidak banyak masyarakat Batak Toba
\end{abstract}

\footnotetext{
${ }^{1}$ Mahasiswa Program Pascasarjana ISI Yogyakarta.
} 
yang mengerti tentang makna nyanyian andung yang sebenarnya. Untuk itu bahasa andung yang seharusnya digunakan dengan hata andung tidak lagi digunakan, sehingga sudah tidak memiliki nilai tradisi yang melekat pada masyarakat Batak Toba di Samosir.Penelitian ini dilakukan selama kurun waktu empat bulan, dari mulai bulan Februari 2017 hingga Mei 2017.

Untuk membahas persoalan tersebut maka digunakan teori Abdul Chaer dalam mengkaji fungsi dan makna, nilai-nilai budaya yang terdapat dalam nyanyian andung sarimatua Отри Juan Boru. Hasil dari penelitian ini menghasilkan beberapa kesimpulan diantaranya nyanyian andung kurang memiliki eksistensi pada masyarakat Batak dikarenakan, para penutur andung pada upacara kematian masyarakat batak Toba pada saat sekarang sudah sangat sulit ditemukan. Tradisi andung ini dianggap tidak sesuai lagi untuk jaman sekarang. Beberapa faktor yang mengakibatkan pergeseran dan perubahan pada tradisi andung sarimatua saat ini adalah agama, bahasa, dan penggunaan alat musik.

Fungsi dari tradisi andung pada saat sekarang dalam upacara kematian masyarakat Batak Toba antara lain: fungsi ekspresi kesedihan dan kedekatan hubungan serta penghormatan terhadap keluarga yang meninggal. Makna yang terkandung dalam andung sarimatua mengungkapkan seluruh perasaan dan menceritakan isi hatinya kepada ibunya yang sudah meninggal dunia, menceritakan banyak hal, kerinduan sipangandung terhadap paman dan kakek yang sudah lama meninggal pun turut diungkapkan dan menitip salam kepada mereka, serta mengharapkan ibunya masih tetap dapat melindungi para keturunannya. Nilai-nilai budaya yang terdapat pada tradisi andung dalam upacara kematian sarimatua masyarakat Batak Toba saat ini yaitu nilai hasangapon, hagabeon, dan hamoraon.

Kata Kunci: Andung, Kematian Sarimatua, Batak Toba.

\section{Pendahuluan}

Masyarakat Indonesia termasuk masyarakat yang multikultural. Multikultural dapat diartikan sebagai keragaman atau perbedaan terhadap berbagai kebudayaan. Keunikan dan keanekaragaman budaya pada masing- masing etnis tersebut telah memunculkan bermacam bentuk seni, salah satunya adalah seni sastra. Sastra merupakan suatu wujud dan hasil dari kebudayaan. Dalam kehidupan masyarakat, sastra dan kebudayaan memperoleh tempat khusus, karena terjadinya hubungan erat di antara keduanya. Sastra sebagai karya seni merupakan bagian integral suatu masyarakat, sedangkan masyarakat itu sendiri merupakan pemilik suatu kebudayaan.

Sastra lisan ini dituturkan, didengarkan, dan dihayati secara bersama-sama pada peristiwa tertentu, dengan maksud dan tujuan tertentu pula yang berkaitan dengan siklus hidup. Seni sastra yang dimaksudkan adalah dalam bentuk ratapan, seperti halnya dalam surat kabar Medan bisnis daily.com 19 Januari 2018, bahwa seperti halnya di Papua khususnya masyarakat Sentani, ratapan itu disebut remahili (ratapan itu adalah 
kebiasaan-kebiasaan atau budaya ketika ada sanak keluarga meninggal dunia, saudara dan kerabat lain datang dan meratapi bersama keluarganya sambil bernyanyi dan meratapi kepergian saudara dan keluarga mereka) yang dilakukan ketika ada satu peristiwa duka cita, sebagai ekspresi kesedihannya. Kata-kata yang disampaikan biasanya berupa ungkapan kesedihan, penyesalan maupun pengaduan terhadap Tuhan. Begitu juga dengan masyarakat Toraja, Sulawesi Selatan. Ratapan kesedihan yang disebut kadong badong tosarani (kata-kata ratapan yang biasa dipakai dalam sebuah upacara adat kematian dari daerah Toraja), untuk mengiringi upacara kematian seseorang. Kata-kata yang diucapkan sambil menangis itu pada intinya mengungkapkan kenangan atau riwayat hidup orang yang telah meninggal tersebut. Demikian juga halnya dengan yang terjadi pada masyarakat Batak Toba. Ekspresi kesedihan itu dikenal dengan sebutan andung.

Andung berisi ungkapan kesedihan atau penderitaan hidup yang dialami seseorang. Wujud kesedihan, misalnya pada saat kematian orang tua, dan anggota keluarga. Andung dan Andung-andung pada umumnya umumnya mempunyai ritme yang sama dengan andung, namun berbeda dalam hal tujuannya. Didalam andung bahasanya menggunakan hata andung, sedangkan andung-andung tidak harus menggunakan hata andung, dan tidak berhubungan dengan kematian. Andung-andung menggambarkan tentang perjalanan hidup atau penderitaan seseorang (Sibarani 1999: 84-85). Misalnya dalam bahasa andung anak disebut menjadi 'sinuan tunas' (putra), boru 'sinuan beu' (putri), amang 'parsinuan' (ayah), inang 'pangintubu' (ibu). Pada waktu mangandung, sipangandung mengungkapkan segala keluh kesah di dalam kehidupannya. Nyanyian ratap andung ini pada umumnya sangat terasa ekspresif, menggambarkan kesedihan yang sangat mendalam, dalam lirik lagu andung terdapat makna dan pesan yang terkandung didalamnya. Kegiatan mangandung dapat dilakukan pada saat almarhum baru saja meninggal dunia,dilakukan di sela-sela datangnya para pelayat. Lirik andung yang digunakan dalam andung adalah hata andung bahasa yang digunakan dalam nyanyian andung sarimatua tidak menggunakan bahasa sehari-hari (Batak Toba), melainkan menggunakan bahasa ratapan. Umumnya yang melakukan andung adalah kaum perempuan yang disebut dengan sipangandung (orang yang melakukan ratap), diekspresikan dengan cara spontan. Sipangandung harus dapat menguasai hata andung dan menggunakannya dengan benar. Sipangandung biasanya menutupi kepalanya dengan kain ulos (kain tenun khas Batak Toba berbentuk 
selendang). sehingga tidak tampak mimik wajahnya ataupun kemungkinannya meneteskan air mata. Tujuan dari tradisi mangandung bagi masyarakat Batak Toba tidak hanya sekedar menceritakan pengalaman hidup orang yang meninggal tersebut, tetapi dalam andung terdapat nasihat-nasihat penting bagi keluarga yang ditinggalkan, harapan-harapan, dan juga ungkapan syukur kepada Tuhan. Karena nilai-nilai budaya menjadi bagian penting dalam tradisi andung. Dalam kehidupan manusia tidak terlepas dari persoalan nilai, nilai merupakan sifat atau hal-hal yang penting atau berguna bagi kehidupan manusia. Nilai budaya nonmaterial masyarakat Batak Toba secara khusus yang mencakup segala aspek kehidupan orang Batak, yang dianggap penting dan berharga terdiri dari tiga nilai budaya utama, ketiga nilai budaya tersebut adalah: hagabeon, hasangapon, dan hamoraon. Andung juga memakai beberapa macam ikon tangisan, dalam hal mangandung, sipangandung akan menggerakkan tangannya secara teratur dan berulangkali, yaitu dari arah orang yang meninggal tersebut kearah jantungnya sendiri dengan makna untuk mengambil sahala (adalah jiwa atau roh kekuatan yang dimiliki seseorang. Semua orang memiliki tondi, tetapi tidak semua orang memiliki sahala. Sahala sama dengan sumanta, tuah atau kesaktian yang dimiliki para raja atau hula-hula. dari orang yang sudah meninggal tersebut kepada dirinya atau kepada keturunannya, gerakan ini disebut mangalap tondi ninamate/mangalap sahala ni na mate (mengambil dan berusaha memiliki kekuatan dari roh dari orang yang sudah meninggal). Pada saat sekarang ini, andung dalam upacara adat kematian sarimatua pada masyarakat Batak Toba sudah jarang dilakukan, dan sipangandung juga sudah jarang ditemukan.

Pada umumnya yang ditemui pada acara kematian sarimatua saat sekarang lebih dominan tangisan biasa dan mangangguk bobar (tangis terisak-isak), jika ada yang dapat mangandung tidak lagi menggunakan hata andung, melainkan menggunakan bahasa Batak Toba sehari-hari (hata somal), sipangandung juga dalam andung-nya menggunakan bahasa Indonesia, dan juga sipangandung sudah tidak mengetahui fungsi dan makna andung yang disampaikan dalam nyanyian andung sarimatua tersebut. Dewasa ini mulai menunjukkan gejala perubahan yang mengkhawatirkan, yaitu kurangnya kepedulian masyarakat Batak Toba terhadap suatu tradisi, khususnya tradisi andung.

Hampir dapat dipastikan bahwa tradisi andung sebagai tradisi lisan bagi masyarakat Batak Toba tersebut makin lama makin berkurang dengan berkurangnya 
masyarakat pendukung sebagai akibat perkembangan jaman dan teknologi yang sudah semakin maju (Analisa, 24 Desember 2017). Generasi muda sekarang menganggap tradisi andung adalah tradisi yang sudah ketinggalan jaman. Permasalahan diatas tersebut didukung juga dengan pernyataan Ketua Asosiasi Tradisi Lisan (ATL) Pudentia MPS mengatakan pewarisan tradisi lisan tidak berjalan dikarenakan generasi muda sekarang banyak yang tidak tertatrik dengan tradisi lisan tersebut. Hal ini bisa jadi akibat tradisi lisan ini tidak dibawa dalam konteks kekinian (Kompas, 12 April 2011).

\section{Eksistensi Andung Sarimatua}

Eksistensi atau keberadaan andung dalam setiap upacara kematian saat ini sudah jarang ditemukan khususnya di wilayah Kabupaten Samosir. Dengan adanya perubahan yang di pengaruhi oleh perubahan sosial budaya, dan juga mobilitas jaman yang berkembang semakin cepat, sangat berpengaruh terhadap kehidupan sosial masyarakat Batak Toba. Pada upacara kematian saat sekarang yang paling sering dijumpai adalah anggota keluarga yang mangangguk bobar (menanggis terisak isak). Berdasarkan hasil pengamatan di lapangan, peneliti melihat beberapa faktor yang mengakibatkan perubahan pada tradisi andung sarimatua saat ini.

\section{Agama}

Pemahaman gereja tentang makna andung dalam upacara kematian sarimatua adalah sebagian dari kehidupan jemaat HKBP Simanindo, sebelum masuk kekristenan dalam kehidupan masyarakat Batak Toba, kebudayaan telah dilakukan oleh leluhur. Adat kebudayaan masyarakat Batak Toba sangat baik untuk dilakukan apalagi upacara sarimatua, sebab dalam pelaksanaan upacara sarimatua gereja ikut berperan memulai dan menutup upacara tersebut untuk memberikan arahan terhadap pihak yang melakukan bahwa upacara itu sebagai tanda ucapan terimah kasih terhadap Tuhan dan supaya Tuhan yang hadir dalam diri keluarga agar keluarga bersatu dan berdamai.

Pergeseran dan perubahan terjadi setelah masuknya agama kristen oleh bangsa Eropa ke Tanah Batak, misionaris ini menganggap bahwa 'mangandung' adalah perbuatan yang menunjukkan kekurang percayaan kepada Tuhan, sehingga mangandung diidentikkan dengan keputusasaan. Dalam hasil penelitian yang peneliti lakukan, saat upacara kematian Ompu Juan Boru, di mana Ompu Juan Doli (suami), dan semua anakanaknya maupun keluarga besar Sitanggang menanggis menceritakan kisah perjalanan 
Отри Juan Boru bersama keluarga semasa hidupnya, kemudian pihak Gereja mengambil buku ende (buku nyanyian Gereja) mengajak para pelayat dan seluruh keluarga untuk bernyanyi bersama- sama.

\section{Bahasa}

Perubahan yang paling nyata adalah bahasa andung. Bahasa yang dipergunakan dalam andung sarimatua berbeda dengan bahasa sehari-hari. Tujuan pemakaian bahasa ini adalah memperdalam makna yang diungkapkan yang disebut hata andung. Andung sebagai salah satu warisan budaya yang pernah hidup dan berperan kuat didalam masyarakat Batak Toba yang sampai saat ini masih dipakai.

Seperti halnya pada upacara kematian Отри Juan Boru di desa Unjur, Ompu Juan Doli yang merupakan suami dari Oтри Juan boru yang meninggal tidak dapat mangandung dengan menggunakan hata andung yang dapat dilakukannya adalah hanyalah menanggis terisak-isak (mangangguk bobar), begitu juga dengan anak dan putrinya, tetapi salah satu dari puterinya, yaitu Rosinta boru Sitanggang tampil sebagai sipangandung untuk mangandungi jasad ibunya. Rosinta boru Sitanggang mangandungi sambil mengelus dagu, membelai rambut, mengusap wajah, mencium pipi, memegang tangan, bahkan mencium kaki ibunya sambil melakukan ratap. Dalam lirik andung-nya, tidak lagi menggunakan hata andung melainkan bahasa Batak Toba dan juga bahasa Indonesia, teks andung Rosinta menceritakan kenangan hidup yang dialami sipangandung dengan ibunya. berikut adalah teks andung Rosinta boru Sitanggang.

Omak, selamat jalan ma di Ho

Omak Selamat tinggal ma di

hami Omak

Molo adong rupani salanghu Omak, Maafhon

au Omak Omak Omak e, Semua pesanmu

Omak, kuingat semua Berikan kami

kesehatan, Omak

Biar bisa kuturuti amanahmu, Omak

Omak, Omak, Omak e maafkanlah salahku, Omake 
kalau aku punya salah, Omak, Omake

Omak, Omak e, molo pajumpang ho dohot Tulang dohot

Ompung, Omak, Omak e, kirim salam ma au, Omak

Sai didokhon ho do: Ompungmu nunga ro, dohot Tulangmu ro

mangalap au Omak e, mungkin dang mangolu be au, hape toho do

Omak

Omak, Omak, Selamat tinggal, Omak, selamat jalan Omak

Maafkan aku kalau punya salah, Omak

Selamat jalan Omak, selamat tinggal ma di

hami Angka pahOmpum on dohot angka

helam on Omak, Omak e, tengoklah

borumu ini, Omake."

Terjemahan:

Ibu, Selamat jalanlah untukmu oh

Ibu Selamat tinggallah untuk kami

oh Ibu

Kalau ada salah yang aku perbuat maafkan

aku Ibu Ibu, Ibu, semua pesanmu Ibu, kuingat

semuanya Berikanlah kami kesehatan, Ibu

Supaya dapat kuturuti semua amanahmu,

Ibu Ibu, Ibu, oh Ibu, maafkanlah

salahku, Ibu Kalau aku punya salah Ibu

oh Ibu

Ibu, oh Ibu, kalau engkau bertemu dengan paman dan

kakek, Ibu, oh Ibu, titip salamku pada mereka, Ibu

Sering engkau mengatakan: Kakek dan Pamanmu sudah datang

menjemput aku Oh Ibu, mungkin hidupku tidak lama lagi, ternyata

benar, oh Ibu

Ibu, Ibu, selamat tinggal, Ibu, selamat

jalan Ibu Maafkan aku kalau punya salah,

Ibu

Selamat jalan Ibu, selamat tinggal bagi

kami Begitu juga cucu dan menantumu

Ibu, oh Ibu, lihatlah putrimu ini, oh Ibu

Rosinta boru Sitanggang mengatakan kesulitan yang dialami dalam mempelajari hata andung pada saat sekarang adalah di mana orangtuanya sudah tidak mengajarkan lagi kepadanya hata andung, dan bahasa Batak Toba tidak dibiasakan dalam keluarga sebagai alat komunikasi, faktor lain adalah Rosinta sudah lama merantau dan tinggal lama di Jakarta. Rosinta sendiri sudah jarang menggunakan bahasa Batak Toba sebagai alat 
komunikasi sehari-hari dalam keluarganya, bahkan dalam berkomunikasi sehari-hari sudah menggunakan bahasa Indonesia.

\section{Fungsi dan Makna Lirik Nyanyian Andung Sari Matua}

\section{Fungsi Ekspresi Kesedihan}

Syair-syair andung Rosinta boru Sitanggang dialamatkan kepada Ibunya dan kepada paman dan kakeknya. Hal ini terlihat pada andung Rosinta boru Sitanggang.

Omak, Omak e, molo pajumpang ho dohot Tulang dohot

Ompung, Omak, Omak e, kirim salam ma au, Omak

Sai didokhon ho do: Ompungmu nunga ro, dohot Tulangmu ro mangalap au

Omak e, mungkin dang mangolu be au, hape toho do Omak

Terjemahan:

Ibu, oh Ibu, kalau engkau bertemu dengan paman dan kakek, Ibu, oh Ibu, titip salamku pada mereka, Ibu

Sering engkau mengatakan: Kakek dan Pamanmu sudah datang menjemput aku

Oh Ibu, mungkin hidupku tidak lama lagi, ternyata benar, oh Ibu

Makna yang terkandung dalam andung Rosinta boru Sitanggang adalah, dia mengungkapkan seluruh perasaannya dan menceritakan isi hatinya kepada ibunya yang sudah meninggal dunia. Dia melakukan andung sambil menangis menceritakan banyak hal, bahkan tidak hanya berkisar tentang ibunya sendiri. Kejadian-kejadian supranatural seperti diceritakan ibunya, bahwa ibunya sering bertemu dengan almarhum kakek dan paman yang akan menjemputnya. Hal ini menunjukkan bahwa hubungan antara manusia yang masih hidup dengan para kerabatnya yang sudah meninggal masih ada dan hubungan ini juga menentukan hidup manusia itu di dunia dan di akhirat.

Kerinduan Rosinta boru Sitanggang terhadap paman dan kakek yang sudah lama meninggal pun turut diungkapkan dan menitip salam kepada mereka jika ibunya sudah bertemu diakhirat, serta mengharapkan ibunya masih tetap dapat melindungi para keturunannya, andung yang disampaikan Rosinta boru Sitanggang fungsinya hanya untuk menyampaikan isi hatinya saja yang selama ini sudah terganjal lama di dalam hatinya agar di ketahui oleh orang-orang yang hadir melayat pada saat itu, bahkan untuk pihak keluarganya yang mungkin hadir juga disitu. Fungsi komunikasi andung ini menjadi sarana ekspresi kesedihan yang dialami sipenutur andung (Rosinta boru Sitanggang). Rosinta 
mengatakan dia mengandungi memuaskan isi hatinya saja, sekaligus menghormati Ibunya yang sudah meninggal karena kebaikan Ibunya selama hidup, dan juga kakek dan pamannya selama hidupnya.

\section{Kedekatan Hubungan}

Sebagai fungsi sosial, tradisi andung berfungsi untuk mengungkapkan kedekatan hubungan dengan yang meninggal, menimbulkan rasa haru pada waktu terjadi kemalangan, menunjukkan kedekatan hubungan, mengungkapkan perilaku dan perbuatan yang baik dari orang yang meninggal dan sebagai kebanggaan. Rosinta boru Sitanggang mengungkapkan seluruh perasaannya dan menceritakan isi hatinya kepada ibunya yang sudah meninggal dunia. Rosinta boru Sitanggang melakukan andung sambil menangis menceritakan semua isi hatinya kepada Ibunya, meminta maaf kepada Ibunya agar Ibunya mau memaafkannya agar semua pesan-pesan Ibunya sewaktu masih hidup dapat dilaksanakannya. Terlihat pada andung Rosinta boru Sitanggang.

Selamat tinggal ma di hami Omak

Molo adong rupani salanghu Omak, Maafhon au

Omak Omak Omak e, Semua pesanmu Omak,

kuingat semua Berikan kami kesehatan, Omak

Biar bisa kuturuti amanahmu, Omak

Omak, Omak, Omak e maafkanlah salahku, Omak e

kalau aku punya salah, Omak, Omake

Terjemahan:

Ibu, Selamat jalanlah untukmu oh

Ibu Selamat tinggallah untuk kami

oh Ibu

Kalau ada salah yang aku perbuat maafkan

aku Ibu Ibu, Ibu, semua pesanmu Ibu, kuingat

semuanya Berikanlah kami kesehatan, Ibu

Supaya dapat kuturuti semua amanahmu,

Ibu Ibu, Ibu, oh Ibu, maafkanlah

salahku, Ibu

Kalau aku punya salah Ibu oh Ibu Pada hasil penelitian yang peneliti lakukan dan temukan, andung yang dilakukan oleh Rosinta boru Sitanggang sekarang merupakan luapan perasaan sedih saja, penggunaan bahasa Batak Toba (hata somal) dan Bahasa Indonesia yang lebih menonjol. Hata andung yang menjadi ciri khas dalam ratapan kematian Ompu 
Juan Boru tidak lagi tampak pada andung yang disampaikan oleh Rosinta boru Sitanggang. Jadi dapat disimpulkan bahwa fungsi andung saat ini hanyalah sebagai ekspresi kesedihan yang mendalam untuk menghormati keluarga yang meninggal.

\section{Nilai-Nilai Budaya Yang Terdapat Pada Tradisi Andung dalam Upacara Kematian sarimatua Pada Masyarakat Batak Toba Saat Ini.}

Masyarakat Batak Toba, memiliki nilai budaya yang mencakup segala aspek kehidupan masyarakat Batak Toba tersebut. Dalam tradisi andung terdapat nilai-nilai budaya masyarakat Batak Toba seperti yang diuraikan di bawah ini.

\section{Hagabeon}

Hagabeon dalam kebudayaan Batak bermakna banyak keturunan dan panjang umur. Secara tradisional, masyarakat Batak Toba sangat ingin mempunyai anak karena itu sangat sayang kepada anak-anaknya, baik anak laki- laki maupun perempuan. Dalam hal ini keluarga Отри Juan Boru adalah keluarga besar yang memiliki enam orang anak, tiga anaklaki-laki dan tiga anak perempuan. Secara spesifik, nilai hagabeon yang dimiliki Отри Juan Boru sangat kuat dalam rangka kepemilikan penerus garis keturunan bagi suku Batak Toba, yaitu mendapatkan keturunan laki-laki seperti halnya pada Ompu Juan Boru ini yang sudah dikatakan memiliki hagabeon yaitu sudah memiliki banyak keturunan Seperti andung yang disampaikan oleh Rosinta Boru Sitanggang: Selamat jalan Omak, selamat tinggal ma di hami Angka pahOmpum on dohot angka helam on "Selamat jalan Ibu, selamat tinggal bagi kami, Begitu juga cucu dan menantumu”.

\section{Hasangapon}

Hasangapon (kemuliaan, kewibawaan, kharisma) suatu nilai utama yang memberi dorongan kuat untuk meraih kejayaan. Dorongan yang kuat untuk meraih hasangapon, dalam kehidupan masyarakat batak Toba tidak hanya berdasarkan kondisi kini dan masa yang akan datang melainkan juga didasarkan pada pencapaian leluhurnya. Dalam tradisi andung pada upacara kematian sarimatua, nilai budaya hasangapon pun nampak pada keluarga Отри Juan Boru. andung yang dilakukan Rosinta boru Sitanggang adalah sebagai 
penghormatan terhadap ibunya yang sudah meniggal sarimatua, sebagai tanda cinta kasih orang tua dan anak dan sebaliknya, mengingat nilai-nilai keteladanan yang diberikan orang tuanya selama hidup terhadap anak-anaknya bahwa nilai keteladanan itu sangat berharga. Terlihat dalam andung Rosinta boru Sitanggang. Omak Omak e, Sетиa pesanmu Omak, kuingat semиa Berikan kami kesehatan, Omak Biar bias kuturuti amanahmu, Omak. "Ibu, Ibu, semua pesanmu Ibu, kuingat semuanya Berikanlah kami kesehatan, Ibu Supaya dapat kuturuti semua amanahmu, Ibu".

\section{Hamoraon}

Hamoraon menunjukkan bahwa tujuan dalam hidup seorang Batak adalah mensejahterakan kehidupan. Dalam hasil penelitian yang peneliti lakukan bahwa Отри Juan Boru sudah mencapai 3H "hagabeon, hasangapon, hamoraon". Hal ini dapat dilihat dari kehidupan keluarga Отри Juan dengan keluarganya termasuk keluarga yang dihormati dan taat beragama. Memiliki anak laki-laki dan anak peremupan, menantu, serta memiliki cucu dari anak laki-laki maupun cucu dari anak perempuan. Semua itu adalah kekayaan (hamoraon) dari Ompu Juan.

\section{Kesimpulan}

Berdasarkan analisa terhadap hasil penelitian yang telah diperoleh penulis, maka dapat diambil kesimpulan bahwa:

1. Nilai-nilai budaya yang terdapat pada tradisi andung dalam upacara kematian sarimatua masyarakat Batak Toba saat ini yaitu nilai hasangapon, hagabeon, dan hamoraon. Istilah hagabeon berarti mempunyai keturunan terutama anak lakilaki, hamoraon berarti "kekayaan atau kesejahteraan", dan hasangapon berarti "kehormatan". Untuk mencapai hagabeon, orang harus menikah: untuk mencapai hamoraon, orang harus mandiri, kerja keras, gotong royong, dan berpendidikan, Oleh karena hagabeon, hamoraon, hasangapon itu merupakan nilai budaya masyarakat Batak Toba.

2. Fungsi dan makna andung dalam konteks upacara kematian sarimatua masyarakat Batak Toba saat ini adalah: fungsi ekspresi kesedihan dan kedekatan hubungan serta penghormatan terhadap keluarga yang meninggal. Makna yang terkandung dalam 
andung Rosinta boru Sitanggang mengungkapkan seluruh perasaannya dan menceritakan isi hatinya kepada ibunya yang sudah meninggal dunia, menceritakan banyak hal, kerinduan Rosinta boru Sitanggang terhadap paman dan kakek yang sudah lama meninggal pun turut diungkapkan dan menitip salam kepada mereka, serta mengharapkan ibunya masih tetap dapat melindungi para keturunan

\section{Daftar Pustaka}

Batu Bara Junita "VIO: Opera Monolog” Etnomusikologi Volume 2 no 1 Mei 2006.

Chaer, Abdul. 2014 Sosiolinguistik Perkenalan Awal, Jakarta: PT RinekaCipta .2013 Linguistik Umum, Jakarta: PT Rineka Cipta 1994 Lingusitik Umum, Jakarta: PT Rineka Cipta

Flora, Hotmaida. Makna Simbol Andung (Ratapan) dalam Upacara Pemakaman Adat Batak Toba di Pekanbaru. JOM FISIP Volume 1 no. 2 Oktober 2014.

Harahap, B.H. dan Hotman M Siahaan.1987. Orientasi Nilai-nilai Budaya Batak. Jakarta: Sanggar Willem Iskandar.

Hodges, Wiliam Robert JR. 2009. Ganti Andung Gabe Ende (Replacing Laments Becocing Hymns) The Changing Voice Of Grief In The-Prefrenureal Wakes of Protestant Toba Batak North Sumatra Indonesia). Santa Barbara University Of California

Junia, Eva. Upacara Kematian Saur Matua Pada masyarakat Batak Toba (Studi Kasus Tentang Kesiapan Keluarga) Di Desa Purbatua Kecamatan Purbatua Kabupaten Tapanuli Tengah. JOM FISIP Volume 3 no 1 Februari 2001.

Koenjaraningrat, 1970. Manusia dan Kebudayaan di Indonesia, Jakarta: Djambatan. 1987. Pokok-Pokok Antropologi, Jakarta: PT. Dian Rakyat. Djambaran . 1980. Pengantar Antropologi,P.D. Aksara, Jakarta: 
Lomax, Alan. 1968. Folk Song Style and Culture. Washington DC: American Association For The Advancement of Science.

Lotar Schreiener. 2008. Perjumpaan Adat Dan Iman Kristen DiTanah Batak.Jakarta: BPK Gunung Mulia

Lumongga, Pardede, R, A. 2010. Masisisean Di Ulaon Adat. Medan: CV. Tulus Jaya

Moleong. 1990. Metodologi Penelitian Kualitatif. Bandung: PT Remaja Rosdakarya.

Panggabean, Ance Juliet. Peran Gondang Sabanunan BatakToba Pada Upacara Kematian Saur Matua di Kota Medan dan Beberapa Aspek Yang Mempengaruhinya. Jurnal Visi Volume 16 No1 Februari 2008, Universitas HKBP Nomensen.

Pasaribu M Ben, 2006 “Musik Populer" Jakarta: Lembaga Pendidikan Seni Nusantara,

Pedersen Paul B. 1975. Darah Batak dan Jiwa Protestan, Jakarta: BPK Gunung Mulia.

Pinem, Kamarlin. Upacara Adat Kematian Cawir Metua Pada Etnis Karo di Desa Kutanggung Kecamatan Juhar. Jupis Volume 5 Juni 2013, Jurusan Pendidikan Geografi, Fakultas Ilmu Sosial UNIMED.

Poerwanto, Hari. 2006 "Kebudayaan dan Lingkungan, Dalam Perspektif Antropologi

Rachman. 1993, Strategi dan Langkah-langkah Penelitian Pendidikan, IKIP Semarang Press, Yogyakarta.

Raja Marpodang Gulton.1992. Dalihan Na ToluNilai Budaya Batak (tiga tungku) yaitu: Hula-hula, Dongan Tubu, Boru. Medan: CV. Armada.

Siahaan, N. 1964. Sedjarah Kebudajaan Batak. Medan

1982. Adat Dalihan Na Tolu: Prinsip dan Pelaksanaannya. Jakarta: Grafindo.

Sibarani, R. 2012. Kearifan Lokal Hakikat, Peran, dan Metode Tradisi Lisan. Jakarta: Asosiasi Tradisi Lisan (ATL). 
Sihombing, T. M. 1986. Filasafat Batak Tentang Kebiasaan-kebiasaan Adat Istiadat Jakarta: Balai Pustaka.

Simatupang, Defi Elias. Konsep Kematian Ideal Pada Masyarakat Batak Toba (Studi Entoarkeologi). Jurnal Penelitian Bidang Pendidikan Volume 17. April 2001

Sinaga, Richard, 1999. Meninggal Adat Dalihan Na Tolu. Jakarta: Dian Utama.

. 1987. Leluhur Marga Batak, dalam Sejarah, Silsilah dan Legenda. Jakarta: Dian Utama

Sitanggang. JP. 2014. Batak Na Marserak (Orang Batak Yang Terpencar). Jakarta: Raja Napogos.

Soemardjan, Selo. 1982. Teori Sosiologi Tentang Pribadi dalam Masyarakat. Jakarta: Ghalia Indonesia.

Suriasumantri, S Jujun. 2003, Ilmu dalam Perspektif, Jakarta: Yayasan Obor Indonesia.

Usman, Husaini dan Purnomo Setiady Akbar. (2009). Metode Penelitian Sosial. Jakarta: PT. Bumi Aksara.

Vergouwen, J.C. 2004. Masyarakat dan Hukum Adat Batak Toba. LKIS. Yogyakarta.

W. Robert Hodges, “Tu Dia Ho, Dung Mate Ho?” Manifestasi dan Mediasi disonansi kognitif dalam konteks lagu-lagu ratapan di Kalangan Kristen Protestan Batak Toba. Jurnal Etnomusikologi Volume 2 no 1 Mei 2006.

Wierzbicka, A. 2010. Experience, Evidence dan Sense: Oxford: Oxford University Press. 
